\title{
PEMODELAN BUS SURABAYA (MOVING MODA SEBELUM KE SUROBOYO BUS)
}

\author{
Gaspar Y. K. Tuames ${ }^{1 *}$ \\ 1 Jurusan Teknik Sipil, Fakultas Teknik Sipil Lingkungan dan Kebumian, Institut Teknologi Sepuluh Nopember \\ (ITS) \\ JI. Arief Rahman Hakim, Surabaya 60111 \\ E-mail: tuames_gaspar@yahoo.com
}

\begin{abstract}
Abstrak
Masalah transportasi di Kota Surabaya bersifat kompleks karena tingkat pertumbuhan prasarana jalan yang tidak sebanding dengan peningkatan jumlah pergerakan. Hal ini ditunjukkan dengan semakin padat dan menyebabkan kemacetan dimana-mana, untuk itu pemerintah kota Surabaya harus dapat memaksimalkan sarana transportasi masal umum. Dengan adanya permasalahan tersebut juga mendorong pemerintah untuk mampu menyediakan fasilitas transportasi umum yang aman, nyaman, tepat waktu, dan dapat menjangkau pusat-pusat kegiatan di Kota Surabaya. Oleh karena itu untuk mengalihkan masyarakat dari kendaraan pribadi ke angkutan umum, disediakanlah moda transportasi umum berupa Bus Suroboyo yang didesain dengan aman dan senyaman mungkin supaya dapat menarik masyarakat untuk menggunakannya. Penelitian ini menggunakan pendekatan metode Ability To Pay (ATP) dalam menganalisis tarif. Hasil penelitian menunjukkan bahwa nilai ability to pay (ATP) maksimum adalah Rp 10,416.67, minimum Rp 1,875.00 dan rata-rata Rp 4,902.19.
\end{abstract}

Kata kunci: Ability To Pay (ATP), Bus Suroboyo, Transportasi Umum.

\section{PENDAHULUAN}

Dikenal sebagai kota pahlawan, Surabaya juga merupakan kota terbesar kedua di Indonesia setelah Jakarta. Perkembangan yang begitu pesat dari tahun ke tahun, terutama perkembangan perekonomian dan perkembangan jumlah penduduk. menjadikan Surabaya sebagai salah satu prioritas tujuan bisnis bagi banyak orang dalam mencari pekerjaan, baik bagi penduduk kota Surabaya sendiri atau bahkan penduduk dari berbagai kota dari luar wilayah Surabaya. Akibatnya terjadi peningkatan pergerakan orang maupun barang sehingga menimbulkan masalah kemacetan di berbagai titik. Demi hal itu pemerintah Surabaya dituntut harus memaksimalkan moda transportasi umum untuk mengalihkan pengguna kendaraan pribadi untuk lebih menggunakan angkutan umum.

Transportasi umum yang tepat waktu dan nyaman tanpa terkendala macet akan menjadi daya Tarik yang kuat bagi masyarakat. Namun kenyataannya kebanyakan orang malas untuk menggunakan jasa transportasi umum, kebanyakan dari mereka lebih memilih untuk menggunakan kendaraan pribadi untuk pergi ke tempat tujuan terutama ke tempat kerja. Berbagai faktor menjadi penyebab orang malas menggunakan angkutan pribadi, di antaranya tarif yang masih dianggap tidak cocok dengan pelayanan, durasi perjalanan maupun waktu yang tidak tentu, sarana dan prasaran transportasi umum yang tidak memadai, informasi mengenai rute tidak tersampaikan dengan baik dan bahkan konektivitas antar angkutan umum yang tidak jelas sehingga membuat masyarakat enggan menggunakan angkutan umum. Dengan adanya permasalahan tersebut juga mendorong pemerintah untuk mampu menyediakan fasilitas transportasi umum yang aman, nyaman, tepat waktu, dan dapat menjangkau titik-titik yang menjadi pusat kegiatan di Kota Surabaya.

Dengan adanya permasalahan tersebut juga mendorong pemerintah untuk mampu menyediakan fasilitas transportasi umum yang aman, nyaman, tepat waktu, dan dapat menjangkau pusat-pusat kegiatan di Kota Surabaya. Untuk menarik minat masyarakat di Kota Surabaya untuk menggunakan angkutan umum, Bus Suroboyo sebagai moda transportasi umum disediakan oleh pemerintah kota Surabaya. Bus ini didesain agar menyediakan pelayanan yang senyaman mungkin bagi penggunanya agar dapat menarik minat masyarakat Surabaya untuk menggunakannya

Kehadiran Bus Suroboyo maka perlu dikakukan penelitian tentang karakteristik 
penumpang Bus Suroboyo dan moda yang digunakan sebelum berpindah, faktor yang mempengaruhi penumpang untuk berpindah menggunakan Bus Suroboyo, termasuk penentuan tarif yang akan diberlakukan. Tarif Bus Suroboyo harus dapat dijangkau oleh pengguna, dengan kata lain layanan yang disediakan disesuaikan dengan daya tingkat kemampuan masyarakat dalam membayar tarif dengan mempertimbangkan keberlangsungan operasi dari Bius Suroboyo dan peningkatan usaha layanan bus demi perkembangan kedepan yang lebih baik. Dari uraian di atas, penulis mencoba untuk menganalisis tarif Bus Suroboyo dengan pendekatan metode Ability To Pay (ATP).

\section{METODE PENELITIAN}

Penelitian ini menggunakan metode survei state preference. Survei dilakukan dengan cara menyebarkan kuesioner yang berfungsi untuk mengumpulkan data dari penumpang Bus Suroboyo berupa karakteristik umum responden, kemampuan membayar dan keinginan membayar penumpang Ability To Pay (ATP).

Penentuan variabel penelitian pada Ability To Pay (ATP) yaitu Penghasilan keluarga per bulan dan alokasi biaya transportasi. Variabel- variabel ini selanjutnya akan digunakan untuk membentuk kuesioner.

Analisis regresi logistik biner (binary logistic regression) digunakan untuk mengetahui persentase probabilitas responden yang bersedia untuk berpindah moda/kendaraan dari moda yang digunakan sebelumnya kemudian beralih menggunakan Bus Suroboyo. Selain itu, analisis regresi logistik biner juga dapat digunakan untuk mengetahui faktor - faktor yang dapat mempengaruhi responden untuk berpindah moda. Sebelum diketahui faktor - faktor yang mempengaruhi kesediaan untuk berpindah moda, terlebih dahulu dilakukan pengujian untuk setiap variabel bebas dengan menggunakan regresi logistik biner untuk mengetahui signifikan atau tidaknya variabel bebas (independent variables) terhadap variabel terikat (dependent variables) yang berupa kesediaan responden untuk berpindah moda

\section{HASIL DAN PEMBAHASAN}

Berdasarkan rekapitulasi hasil survei total responden dari Bus Suroboyo adalah 51 responden. Dari hasil survei yakni dari 51 responden yang ingin berpindah moda dari moda sebelum ke Bus Soroboyo adalah sebayak 44 orang dan yang tidak mau. Dari hasil survei diperoleh moda yang digunakan sebelumnya (moda asal) adalah sepeda motor, mobil pribadi, Damri/bus kota, dan ojek online. Pada Gambar 2 menunjukkan bahwa responden yang ingin berpindah ke Bus Suroboyo adalah yang menggunakan sepeda motor dan Damri / bus kota sedangkan yang menggunakan mobil pribadi dan ojek online tidak mau berpindah ke Bus Suroboyo. berpindah sebanyak 7 orang.

Dari hasil survei diperoleh moda yang digunakan sebelumnya (moda asal) adalah sepeda motor, mobil pribadi, Damri/bus kota, dan ojek online. Jumlah moda sebelumnya dapat dilihat pada Gambar 3

Dari hasil survei dan analisa data responden yang ingin berpindah ke Bus Suroboyo adalah yang menggunakan sepeda motor dan Damri / bus kota sedangkan yang menggunakan mobil pribadi dan ojek online tidak mau berpindah ke Bus Suroboyo. Data perpindahannya dapat dilihat pada Tabel 1

Tabel 1 Responden Yang Ingin Berpindah Moda

\begin{tabular}{lcc}
\hline $\begin{array}{c}\text { Moda } \\
\text { Sebelumnya }\end{array}$ & $\begin{array}{c}\text { Responden } \\
\text { Yang } \\
\text { Bepindah }\end{array}$ & Persentase \\
\hline Sepeda Motor & 22 & $50 \%$ \\
Mobil Pribadi & 0 & 0 \\
Damri/Bus Kota & 22 & $50 \%$ \\
Ojek Online & 0 & 0 \\
\hline Total & $\mathbf{4 4}$ & $\mathbf{1 0 0 \%}$ \\
\hline
\end{tabular}

Dari hasil analisis perpindahan moda sebelum ke Suroboyo Bus didapatkan model $Y$ $=-2.321 \times$ Moda sebelumnya + 8.399. Dengan hasil negatif $(-2,321)$ ini menunjukkan bahwa moda yang paling banyak berpindah adalah moda awal analisis regresi yaitu sepeda motor. Nilai signifikan dalam analisa ini adalah 0,039< 0,05 sehingga dapat disimpulkan bahwa banyak responden yang ingin berpindah dari moda sebelum ke Bus Suroboyo dengan Koefisien daterminasi $\left(R^{2}\right)$ sebesar 0.374 yang sama dengan $37,4 \%$ angka ini mengandung arti moda yang digunakan sebelumnya berpengaruh 37,4\% terhadap keinginan untuk pindah ke Bus Suroboyo sedangkan sisanya $(100 \%-37,4 \%=62,6 \%)$ dipengaruhi oleh faktor/variabel lain. 


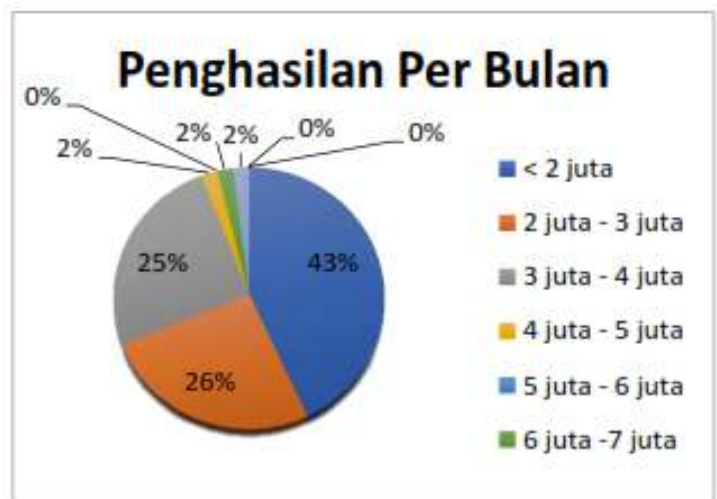

Gambar 1 Penghasilan Penumpang Per Bulan

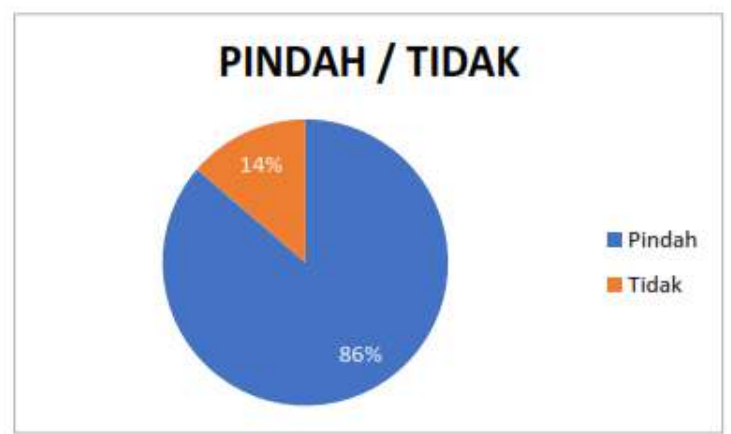

Gambar 2 Responden yang ingin berpindah Bus Suroboyo dan tidak berpidah

\section{PERSENTASE RESPONDEN}

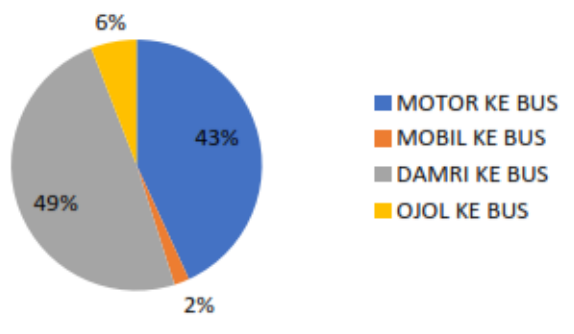

Gambar 3 Moda yang Digunakan Sebelumnya (Moda Asal)

Hasil analisis klasifikasi plot pada Tabel 2 menunjukkan bahwa model regresi logistik yang diperoleh ini dapat memprediksi dengan benar 92,2\% kondisi yang terjadi di lapangan. Maka dari itu model regresi logistik ini cukup baik untuk digunakan.

Tabel 2 Kaslifikasi Plot

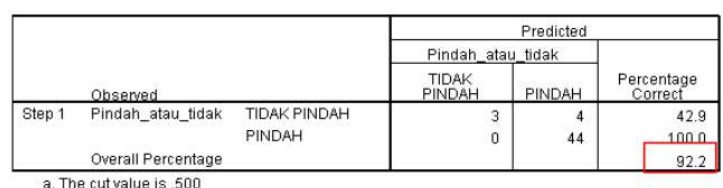

Kemampuan masyarakat ditinjau dari kemampuan (ATP) berdasarkan penghasilan yang diterimanya adalah ATP responden secara keseluruhan tanpa membedakan pendapatan per bulan rata-rata pada Rp. 4,902.19/travel dengan ATP maksimum Rp. 10,416.67/ travel dan ATP minimum Rp. $1,875.00 /$ travel.

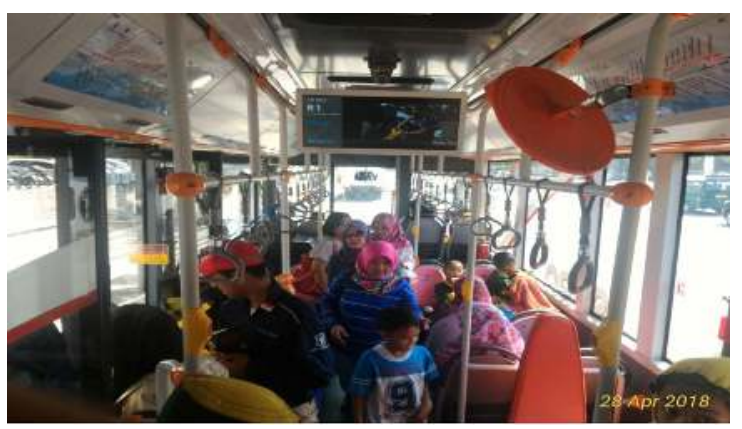

Gambar 4 Suasana dalam Bus Suroboyo

\section{PENUTUP}

Berdasarkan hasil dan pembahasan yang telah dilakukan dapat disimpulkan sebagai berikut:

1. Dari 51 responden yang di survei sebanyak 44 responden yang bersedia pindah ke Bus Suroboyo sedangkan 7 responden tidak bersedia.

2. Moda yang digunakan sebelum adalah sepeda motor, Damri/bus kota, mobil pribadi dan ojek online. Dari ke empat moda ini yang bersedia pindah adalah yang menggunakan sepeda motor (22 respnden) dan Damri /bus (22 responden) dengan probabiltas yang sama yaitu 0,9977 , sedangkan yang menggunakan mobil pribadi dan ojek online tidak bersedia untuk pindah ke Bus Suroboyo.

3. Persamaan yang diperoleh dari hasil analisa regresi untuk moda yang digunakan sebelum terhadap kesediaan berpindah ke Bus Suroboyo adalah sebagai berikut : $Y=-2.321 \times$ Moda Sebelumnya + 8.399. Nilai signifikan dalam analisa ini adalah 0,039 $<0,05$ sehingga dapat disimpulakan bahwa banyak responden yang ingin berpindah dari moda sebelum ke Bus Suroboyo

4. Koefisien determinasi (R2) sebagai berikut 0.374 yang sama dengan $37,4 \%$ angka ini mengandung arti moda yang digunakan sebelummya berpengaruh 37,4 \% terhadap keinginan untuk pidah ke Bus Suroboyo sedangkan sisanya (100\% $37,4 \%=62,6 \%$ ) dipengaruhi oleh faktor/variabel lain. Hasil klasifikasi plot 
menunjukkan bahwa model regresi logistik yang digunakan cukup baik karena mampu menebak dengan benar $92.2 \%$ kondisi yang terjadi.

5. Nilai ability to pay (ATP) maksimum adalah Rp 10,416.67, minimum Rp 1,875.00 dan rata-rata $\mathrm{Rp} 4,902.19$.

\section{DAFTAR PUSTAKA}

Ben-Akiva, M. E., Lerman, S. R., \& Lerman, S. R. (1985). Discrete choice analysis: theory and application to travel demand (Vol. 9). MIT press.

Bruton, M. J. (1985). Introduction to transportation planning.

Permata, M. R. (2012). Analisa Ability To Pay dan Willingness To Pay Pengguna Jasa Kereta Api Bandara Soekarno HattaManggarai. Universitas Indoenesia.

Supriyatno, D., Sulistio, H., Djakfar, L., \& Wicaksono, A. (2012). PERMODELAN KEBUTUHAN TRANSPORTASI MASSAL GUIDED BUSWAY MENGGUNAKAN STRUCTURAL EQUATION MODELING. Jurnal Transportasi, 12(2).

Tamin, O. Z. (2008). Perencanaan, Pemodelan dan Rekayasa Transportasi. Bandung: ITB.

Wicaksono, Y. I., Riyanto, B., \& Kusumastuti, D. R. (2006). ANALISIS KEMAMPUAN MEMBAYAR TARIF ANGKUTAN KOTA (Studi Kasus Pengguna Jasa Angkutan Kota pada Empat Kecamatan di Kota Semarang). Media Komunikasi dan Pengembangan Teknik Sipil, 15(1). 